\title{
Neutrophil-to-lymphocyte ratio and scoring system for predicting coronary artery lesions of Kawasaki disease
}

\author{
Ling-Sai Chang', Yi-Ju Lin', Jia-Huei Yan², Mindy Ming-Huey Guo', Mao-Hung Lo and Ho-Chang Kuo ${ }^{1 *}$
}

\begin{abstract}
Background: Kawasaki disease (KD) causes coronary artery lesions (CAL) and is the leading cause of acquired heart disease in children. The aim of this study is to evaluate the risk factors and set-up a scoring system for predicting CAL of KD.

Methods: We retrospectively reviewed a total of 478 patients diagnosed with KD. We compared age, gender, laboratory data, and treatment response in two groups and developed a scoring system for predicting CAL.

Results: During the study period, 365 of these patients had complete medical records of coronary surveys by echocardiography. Anemia, hypoalbuminemia, C reactive protein (CRP), alanine aminotransferase, neutrophil count, and neutrophil/lymphocyte ratio (NLR) showed significant differences with CAL formation. We determined the cut-off value using a receiver-operating-characteristic $(\mathrm{ROC})$ curve, and following multivariate logistic regression analysis, four independent risk factors demonstrated a significant difference with CAL formation, including CRP > $103 \mathrm{mg} / \mathrm{L}$, NLR $>3.5$, male gender, and intravenous immunoglobulin (IVIG) resistance. We established a score system based on the above evaluation, for which a ROC curve was performed, and a total score of $\geq 2$ points showed a sensitivity of $60.8 \%$ and a specificity of $70.6 \%$, with an area under the ROC curve of 0.696.

Conclusions: Identifying children at risk is important in order to prevent CAL from developing. Four independent risk factors that can predict CAL formation were CRP > $103 \mathrm{mg} / \mathrm{L}, \mathrm{NLR}>3.5$, male gender, and IVIG resistance. This first report incorporated NLR into score systems to predict CAL reinforces previously well-known risk factors for the CAL formation among KD patients.
\end{abstract}

Keywords: CRP, Coronary Artery Lesions, IVIG resistance, Kawasaki Disease, Neutrophil-to-Lymphocyte Ratio, Scoring System

\section{Background}

Kawasaki disease (KD) is an acute febrile illness of unknown etiology characterized by systemic inflammation and vasculitis [1]. The disease most often affects infants between 9 and 11 months [2]. The most significant sequalae of KD is coronary artery lesions (CAL), such as coronary dilatation, aneurysms, narrowing, myocardial infarction, and valvular lesions $[3,4]$. High-dose intravenous immunoglobulin (IVIG) $(2 \mathrm{~g} / \mathrm{kg})$ is the

\footnotetext{
* Correspondence: erickuo48@yahoo.com.tw

'Department of Pediatrics and Kawasaki Disease Center, Kaohsiung Chang Gung Memorial Hospital, Chang Gung University College of Medicine, \#123 Da-Pei Road, Niaosong District, 83301 Kaohsiung, Taiwan

Full list of author information is available at the end of the article
}

standard treatment for $\mathrm{KD}$, and its administration has been shown to significantly decrease the rate of CAL [5]. In patients that do not receive high-dose IVIG treatment, CAL occurrence was $25 \%$, but patients who received high-dose IVIG had CAL occurrence of less than 5\% [6].

Some individuals experience a period of coronary artery dilation after being diagnosed with KD and may experience changes in Z-score. However, new CALs are rarely detected by echocardiography at 6 weeks in KD children with normal measurements at baseline and 2 weeks after IVIG treatment [7]. In Skochko's and Dominguez's cohorts, $75-81 \%$ of patients who have an initial

C C The Author(s). 2020 Open Access This article is licensed under a Creative Commons Attribution 4.0 International License, which permits use, sharing, adaptation, distribution and reproduction in any medium or format, as long as you give appropriate credit to the original author(s) and the source, provide a link to the Creative Commons licence, and indicate if changes were made. The images or other third party material in this article are included in the article's Creative Commons licence, unless indicated otherwise in a credit line to the material. If material is not included in the article's Creative Commons licence and your intended use is not permitted by statutory regulation or exceeds the permitted use, you will need to obtain permission directly from the copyright holder. To view a copy of this licence, visit http://creativecommons.org/licenses/by/4.0/ The Creative Commons Public Domain Dedication waiver (http://creativecommons.org/publicdomain/zero/1.0/) applies to the data made available in this article, unless otherwise stated in a credit line to the data. 
Z-score for the right coronary artery or left anterior descending artery of 2.5 or higher go on to develop coronary artery aneurysm [8, 9]. Therefore, identifying populations at a high risk of CAL is crucial to initiating early intervention. Otherwise, a large aneurysm can develop and lead to mortality and morbidity. Levels of calprotectin are elevated in pediatric patients with giant coronary artery aneurysms one-year post-KD [10]. Improved diagnostic tools and the development of riskspecific anti-inflammatory treatments have enabled intervention research for people at ultra-high risk. Most KD patients with CAL receive very brief treatment due to safety concerns. However, anti-inflammatory medications have not yet been approved for KD children and infants, mainly because exposure to anti-inflammatory medication, such as anti TNF- $\alpha$, cyclosporin, and methylprednisolone pulse therapy, has been associated with such side effects as infection, renal toxicity, and hypertension [11-13]. Meta-analyses revealed that the use of corticosteroids may decrease the incidence of CAL in $\mathrm{KD}[14,15]$. A randomized controlled study on etanercept treatment showed positive improvement in CAL in patients with baseline abnormalities [12]. Another randomized controlled trial reported that adding ciclosporin to high-dose IVIG and aspirin in patients with KD significantly reduced the incidence of CAL $(p=0.010)$ in KD patients at a higher risk for IVIG resistance [11].

$\mathrm{KD}$ is the leading cause of acquired heart disease in children, and many risk factors associated with coronary artery lesions have been reported, including male gender, younger age, older children, IVIG unresponsiveness, and hypoalbuminemia [6, 16-23]. Son et al. developed the risk scores for predicting coronary artery aneurysms in a north American population and validated the score including baseline $\mathrm{Z}$ score $\geq 2.0$, age $<6$ months, Asian race, and C-reactive protein $(\mathrm{CRP}) \geq 13 \mathrm{mg} / \mathrm{dL}$ [24]. Dionne et al. recently showed that adjunctive corticosteroid therapy with IVIG may be protective against progression of coronary artery aneurysms based on Son's score [25]. Tremoulet et al. developed a scoring system for predicting coronary artery aneurysms: illness days $\leq 4$ days, 1 point; bands $\geq 20 \%, 2$ points; $\gamma$ glutamyl transpeptidase $\geq 60 \mathrm{U} / \mathrm{L}, 1$ point; age-adjusted hemoglobin concentrations $\leq-2,1$ point [26]. Sensitivity was $72.2 \%$, specificity was $57.6 \%$, positive predictive value (PPV) was $8 \%$, and negative predictive value (NPV) was $97.5 \%$ at a total score of 2 . Hua et al. reported a scoring system that included the following: male, 1 point; fever duration $\geq 8$ days, IVIG resistance, 1 point; albumin $\leq 35.9 \mathrm{~g} / \mathrm{L}$, 1 point; monocyte $\geq 5.9 \%, 1$ point [17]. The sensitivity and specificity were $51.4 \%$ and $68.2 \%$, respectively, at a cut-off of 3. Many prediction models for IVIG resistance of KD have been developed, but a practical score with high sensitivity and specificity for predicting the risk of CAL in KD patients is still needed. Our aim in this study is to evaluate the risk factors of CAL and set up a scoring system for predicting CAL in KD patients.

\section{Methods}

This study included a total of 478 patients diagnosed with Kawasaki disease at Kaohsiung Chang Gung Memorial Hospital from 2007 to 2018. Of those, 365 patients had complete medical records of coronary artery surveys by echocardiography. KD was diagnosed according to the criteria in the revised diagnostic guidelines for Kawasaki disease (the 5th revised edition) [27]. IVIG resistance was defined based on the published American Heart Association guidelines: "fever persistence $\left(\geq 38{ }^{\circ} \mathrm{C}\right)$ or recurrence greater than 36 hours and up to 7 days following completion of the IVIG infusion."

Of the 365 patients, 40 (11.0\%) were treated with IVIG twice, and 4 patients $(1.1 \%)$ were treated with IVIG three times. During the acute phase, all patients were treated with high-dose IVIG (2 $\mathrm{g} / \mathrm{kg})$ [28]. Laboratory data including complete blood count with differential count, aspartate aminotransferase (AST), alanine aminotransferase (ALT), CRP, albumin, and sodium were investigated, and data were obtained prior to IVIG treatment.

Echocardiography was performed in acute stage, and CAL were defined according to the Japanese Ministry of Health criteria: an internal lumen diameter greater than $3.0 \mathrm{~mm}$ in children of $<5$ years of age or greater than $4.0 \mathrm{~mm}$ in children of $\geq 5$ years of age or an internal diameter at least 1.5 times larger than the diameter of the adjacent segment, or if the morphology of the coronary lumen was obviously irregular, or a z-score $\geq 2.5[3,29]$. We classified the patients into two groups: patients with CAL and patients without CAL [30]. We compared age, gender, laboratory data, and treatment response between the two groups.

Characteristics of patients, clinical features, laboratory data, CAL formation, and IVIG resistance were analyzed with IBM Statistical Product and Service Solutions Statistics 14 (New York, United States) using the MannWhitney test and chi-squared test. $\mathrm{P}<0.05$ was considered statistically significant. A receiver-operatingcharacteristics (ROC) curve was used to define the cutoff of each independent risk factor. Those factors were then analyzed again using binary logistic regression. Factors that showed a significant difference between the two groups were chosen to set-up a scoring system. The sensitivity, specificity, area under the curve of ROC (AUC), and PPV were evaluated through cross analysis.

\section{Results}

We enrolled a total of 365 patients with complete medical records in this study. Tables 1 and 2 present the univariate analysis of the factors associated with CAL. Male gender $(72.4 \%$ vs. $53.8 \%, \mathrm{p}=0.001)$ had a significantly higher percentage in patient with the CAL group than 
Table 1 Clinical characteristics of Kawasaki disease

\begin{tabular}{llll}
\hline & $\begin{array}{l}\text { Patient without CAL } \\
(n=238)\end{array}$ & Patient with CAL $(n=127)$ & $p$ value \\
\hline Age (year) & $1.5(0.8-2.6)$ & $1.4(0.7-2.4)$ & $p=0.316$ \\
Gender (Male) & $128(53.8 \%)$ & $92(72.4 \%)$ & $p=0.001^{*}$ \\
IVIG resistance (+) & $15(6.3 \%)$ & $29(22.8 \%)$ & $p<0.001^{*}$ \\
Clinical features & & & $p=0.504$ \\
Oral changes & $230(96.6 \%)$ & $125(98.4 \%)$ & $p=0.754$ \\
Conjunctival injection & $230(96.6 \%)$ & $124(97.6 \%)$ & $p=1.000$ \\
Extremity changes & $233(97.9 \%)$ & $125(98.4 \%)$ & $p=0.773$ \\
Rash & $230(96.6 \%)$ & $122(96.1 \%)$ & $p=1.000$ \\
Lymphadenopathy & $28(11.8 \%)$ & $15(11.8 \%)$ & $p=0.124$ \\
BCG injection & $130(54.6 \%)$ & $58(45.7 \%)$ & \\
\hline
\end{tabular}

Data are expressed as median (range) or number (percentage). BCG Bacille Calmette-Guerin, CAL Coronary artery lesions, IVIG Intravenous

immunoglobulin; ${ }^{*} p<0.05$

the without CAL group (Table 1). IVIG resistance was observed in $22.8 \%(29 / 127)$ of the CAL group and in $6.3 \%(15 / 238)$ of the no-CAL group during the acute phase $(p<0.001)$ (Table 1$)$. We observed no statistically significant difference in the clinical features between the two groups (Table 1).

No significant difference regarding CAL was found between different ages with cut-offs of 6 months old, 1 year old, 2 years old, and 3 years old (all $\mathrm{p}>0.05$ ) (Table 3 ). However, a higher incidence of CAL was found in younger children ( 6 months old vs. 1 year old vs. 2 year old: $41.7 \%$ vs. $37.5 \%$ vs. $36.3 \%$ ), but this difference did not reach significance $(\mathrm{p}>0.05)$.
Hemoglobin values were significantly lower in the CAL group (hemoglobin $10.96 \pm 0.12$ vs. $11.26 \pm 0.07 \mathrm{~g} /$ $\mathrm{dl}, \mathrm{p}=0.029$ ) (Table 2). The CAL group showed lower serum albumin $(3.59 \pm 0.06$ vs. $3.80 \pm 0.03 \mathrm{~g} / \mathrm{dL}, p=$ $0.005)$. In contrast, CRP $(104.21 \pm 7.29$ vs. $79.31 \pm 4.44$, $p=0.006)$, neutrophil count $(9.10 \pm 0.40$ vs. $7.79 \pm 0.26 /$ $\left.\mathrm{mm}^{3}, \quad p=0.019\right)$, neutrophil/lymphocyte ratio (NLR) (3.95 \pm 0.39 vs. $2.73 \pm 0.15, p=0.004)$, and $\operatorname{ALT}$ ( $92.93 \pm$ 10.14 vs. $74.52 \pm 7.06 \mathrm{U} / \mathrm{L}, p=0.049$ ) were significantly higher in the CAL group in the univariate analysis (Table 2). Both groups had similar leukocytes, platelets, percentage of monocytes, basophils, eosinophils, and lymphocytes, AST, sodium, and platelet/lymphocyte ratio (PLR) during the acute phase.

Table 2 Laboratory data in patients with Kawasaki disease

\begin{tabular}{|c|c|c|c|}
\hline & Patient without $C A L(n=238)$ & Patient with CAL ( $n=127)$ & $p$ value \\
\hline$W B C \times 10^{3} / \mathrm{mm}^{3}$ & $13.07 \pm 0.29$ & $14.14 \pm 0.48$ & $p=0.183$ \\
\hline Hemoglobing/dl & $11.26 \pm 0.07$ & $10.96 \pm 0.12$ & $p=0.029^{*}$ \\
\hline Platelets $\times 10^{3} / \mathrm{mm}^{3}$ & $331.84 \pm 7.29$ & $343.88 \pm 11.11$ & $p=0.248$ \\
\hline Monocyte(\%) & $6.24 \pm 0.23$ & $5.64 \pm 0.24$ & $p=0.359$ \\
\hline Eosinophil(\%) & $3.17 \pm 0.21$ & $3.54 \pm 0.34$ & $p=0.631$ \\
\hline Basophil(\%) & $0.72 \pm 0.14$ & $1.07 \pm 0.20$ & $p=0.061$ \\
\hline AST U/L & $67.95 \pm 6.06$ & $79.16 \pm 10.23$ & $p=0.40$ \\
\hline$A L T U / L$ & $74.52 \pm 7.06$ & $92.93 \pm 10.14$ & $p=0.049^{*}$ \\
\hline CRP $\mathrm{mg} / \mathrm{L}$ & $79.31 \pm 4.44$ & $104.21 \pm 7.29$ & $p=0.006^{*}$ \\
\hline Albuming/dL & $3.80 \pm 0.03$ & $3.59 \pm 0.06$ & $p=0.005^{*}$ \\
\hline Sodium $\mathrm{mEq} / \mathrm{L}$ & $136.35 \pm 0.27$ & $135.27 \pm 0.50$ & $p=0.072$ \\
\hline$P L R$ & $59.39 \pm 4.61$ & $47.37 \pm 2.61$ & $p=0.124$ \\
\hline$N L R$ & $2.73 \pm 0.15$ & $3.95 \pm 0.39$ & $p=0.004^{*}$ \\
\hline Neutrophils $\times 10^{3} / \mathrm{mm}^{3}$ & $7.79 \pm 0.26$ & $9.10 \pm 0.40$ & $p=0.019^{*}$ \\
\hline Lymphocytes $\times 10^{3} / \mathrm{mm}^{3}$ & $3.79 \pm 0.11$ & $3.52 \pm 0.18$ & $p=0.069$ \\
\hline
\end{tabular}

Data are expressed as mean \pm standard errors. ALT Alanine aminotransferase, AST Aspartate aminotransferase, CAL Coronary artery lesions, CRP C-reactive protein, NLR Neutrophil/lymphocyte ratio, PLR Platelet/ lymphocyte ratio, WBC White blood cells; ${ }^{*} p<0.05$. 
Table 3 Cumulative distribution stratified by age

\begin{tabular}{llll}
\hline Age & Patient without $C A L(\boldsymbol{n}=\mathbf{2 3 8})$ & Patient with CAL $(\boldsymbol{n}=\mathbf{1 2 7})$ & $\boldsymbol{p}$ value \\
\hline $\mathbf{6}$ month-old & $24(10.1 \%)$ & $15(11.8 \%)$ & $p=0.599$ \\
$\mathbf{1}$ year-old & $80(33.6 \%)$ & $48(37.8 \%)$ & $p=0.490$ \\
$\mathbf{1 . 5}$ year-old & $122(51.3 \%)$ & $69(54.3 \%)$ & $p=0.584$ \\
$\mathbf{2}$ year-old & $161(67.6 \%)$ & $91(71.7 \%)$ & $p=0.477$ \\
$\mathbf{2 . 5}$ year-old & $173(72.7 \%)$ & $101(79.5 \%)$ & $p=0.164$ \\
$\mathbf{3}$ year-old & $194(81.5 \%)$ & $110(86.6 \%)$ & $p=0.241$ \\
\hline
\end{tabular}

Data are expressed as numbers (percentage). CAL Coronary artery lesions

The Youden index and ROC analysis were applied to determine the cut-off value of CRP levels and NLR as potential predictors for CAL by plotting the proportion of true-positive results (sensitivity) vs. the proportion of false-positive results $(1$ - specificity). To predict CAL, multivariant logistic regression statistics identified four independent risk factors (CRP $>103 \mathrm{mg} / \mathrm{L}, \mathrm{NLR}>3.5$, male gender, and IVIG resistance) based on six variables: $\mathrm{CRP}>103 \mathrm{mg} / \mathrm{L}, \quad$ ALT $>26 \mathrm{U} / \mathrm{L}$, albumin $>3.5 \mathrm{~g} / \mathrm{dL}$, NLR > 3.5, male gender, and IVIG resistance (Table 4). We established a scoring model with four variables: $\mathrm{CRP}>103 \mathrm{mg} / \mathrm{L}$ (multivariant $\mathrm{p}=0.004), \mathrm{NLR}>3.5(\mathrm{p}=$ $0.035)$, male gender $(\mathrm{p}=0.002)$, and IVIG resistance $(\mathrm{p}=$ 0.006 ) using the Youden index with a significant difference between patients with CAL and without CAL based on the above evaluation (Table 4). A score system was set up using the ROC curve. The total risk score was calculated as the sum of the individual scores, and the maximum total score for this risk model was 5 .

Table 5 shows the sensitivity, specificity, PPV, and NPV at each score cut-off. For the risk of CAL, we looked at all cut-off values and used ROC curve to determine the optimal cut-off of a total score of $\geq 2$ points. The sensitivity for this cut-off score was $60.8 \%$, and the specificity was $70.6 \%$ (see Table 5). The analysis resulted in an AUC of 0.696. Higher score implied lower sensitivity and higher specificity. Compared with patients who had a risk score of 0 to 1 , those whose risk score was $\geq 2$ had a much higher risk of having CAL (odds ratio 3.77, 95\% confidence

Table 4 Logistic regression models for differentiating Kawasaki patients with coronary artery lesions from those without coronary artery complications

\begin{tabular}{llll}
\hline & Multivariant $p$ value & Odd ratio (95\% CI) & $\begin{array}{l}\text { Score } \\
\text { point }\end{array}$ \\
\hline Male Gender & $p=0.002$ & $2.35(1.36-4.06)$ & 1 \\
IVIG resistance (+) & $p=0.006$ & $3.12(1.38-7.04)$ & 2 \\
CRP $>$ 103mg/L & $p=0.004$ & $2.25(1.31-3.88)$ & 1 \\
NLR>3.5 & $p=0.035$ & $1.85(1.04-3.28)$ & 1 \\
\hline
\end{tabular}

Cl Confidence interval, CRP C-reactive protein, IVIG Intravenous immunoglobulin, NLR Neutrophil/lymphocyte ratio interval 2.40-5.93). Patients were classified as high risk if their diagnostic score was $\geq 2$; otherwise, they were classified as low risk. The occurrent rate of CAL in the high risk group was $52.74 \%$ in contrast with only $22.83 \%$ in the low risk group. In Table 2, the $\mathrm{p}$ value of albumin was less than 0.05 , so we added albumin as a prediction value. Albumin greater than or equal to $3.5 \mathrm{~g} / \mathrm{dL}$ was equal to one point. The sensitivity of the score predicting CAL was much increased to $72.38 \%$, and specificity was $60.59 \%$ after adding albumin with the cut-off value of the score greater than or equal to two points.

\section{Discussion}

In this study, we demonstrated that male gender, IVIG resistance, anemia, hypoalbuminemia, elevated CRP levels, higher neutrophils count, higher NLR, and higher ALT levels were all risk factors in KD patients who developed CAL. After performing multi-variant logistic regression analysis, we found male gender, IVIG resistance, NLR > 3.5, and CRP $>103 \mathrm{mg} / \mathrm{L}$ to be independent risk factors for predicting CAL formation and then developed a score model. At the cut-off of 2 points, the sensitivity was $60.8 \%$, and the specificity was $70.6 \%$ with an AUC of 0.696. No significant difference was observed regarding CAL formation between different ages and clinical features.

CALs are the most significant complication in KD. Prompt treatment with high-dose IVIG can lower the coronary artery aneurysms rate from $20-25 \%$ to $3-5 \%$. However, $3-5 \%$ patients still develop CAL that need a lifetime of follow-up and treatment. Early classification of patients with high risks can alert the clinician to follow up frequently or to try different anti-inflammatory treatment options, such as steroids [31, 32].

Many researchers have developed score systems for the early detection of IVIG resistance by NLR, but few score systems are for predicting the subsequent CAL formation by NLR [33-35]. In infants younger than one year old, NLR with cut-off value of 2.51 is useful to predict the IVIG resistance [36]. 
Table $\mathbf{5}$ Scoring system for predicting coronary artery lesions

\begin{tabular}{|c|c|c|c|c|c|}
\hline Cut point & $A \cup C$ & Sensitivity & Specificity & $P P V$ & NPV \\
\hline 1 point & 0.696 & $90.4 \%$ & $27.2 \%$ & $39.8 \%$ & $84.2 \%$ \\
\hline 2 points & & $60.8 \%$ & $70.6 \%$ & $52.4 \%$ & $77.2 \%$ \\
\hline 3 points & & $29.6 \%$ & $90.6 \%$ & $62.7 \%$ & $70.8 \%$ \\
\hline 4 points & & $16.8 \%$ & $97.0 \%$ & $75.0 \%$ & $68.7 \%$ \\
\hline
\end{tabular}

AUC Area under the curve of receiver-operating-characteristics, NPV Negative predictive value, PPV Positive predictive value

Nakano et al. demonstrated that age at onset, CRP, and platelet count can all be used to predict patients at a high risk for coronary lesions [37]. Beiser et al. constructed a risk classification tool based on baseline hemoglobin level, neutrophil count, platelet count, and body temperature [38]. Kim et al. found that incomplete KD, IVIG resistance, longer fever duration, and the rs7604693 genetic variant in the PELI1 gene were all risk factors for the formation of CAL [39].

Previous studies found that physical immune system responses to systemic inflammation included marked neutrophilia and lymphocytopenia [40]. Neutrophils indicate active non-specific inflammation, and lymphocytes represent the regulatory pathway of the immune system. Egami score or Kobayashi scores have pointed out the importance of neutrophil percentage for predicting non-responsiveness to IVIG [41]. The NLR represents the balance between inflammation and immune regulation. Amano $\mathrm{S}$ et al. have clearly demonstrated that systemic inflammation occurs in KD patients and mainly affects the cardiovascular system [42]. Therefore, NLR may help reflect systemic inflammation and immune system response in patients with KD. Kee-Soo Ha et al. demonstrated that NLR can predict coronary aneurysm development and IVIG resistance of KD [43]. Furthermore, Seiichiro Takeshita et al. revealed that the combination of NLR $\geq 3.83$ and PLR $\geq 150$ for predicting IVIG resistance in KD has both high sensitivity (72\%) and specificity (67\%) [44]. NLR can be a reliable predictor for IVIG resistance, which can be associated with an increased risk for CAL in children with KD [18]. In our study, NLR is an independent risk factor for CAL formation with the cut-off of NLR > 3.5, but PLR showed no significant difference between patients with CAL and those without CAL. Higher levels of NLR may represent higher inflammation levels and are associated with coronary damage.

This study had some limitations. First, all of our patients were from a single institution, and all of the KD patients were treated with the initial therapy of highdose IVIG. Outcomes may differ from different initial therapies, such as IVIG alone or IVIG plus steroids. However, our laboratory data were all obtained prior to IVIG treatment, so different treatment options may not influence our scoring system. Second, only typical KD patients were included during patient selection, which may have involved some bias. The score might only be used in typical KD patients. Third, it was difficult to know whether these patients had previous cardiac lesions prior to the onset of KD. Another prospective study with more patients with KD will be helpful to confirm our results.

\section{Conclusions}

In this study, we developed a scoring system to predict CAL in KD. Our score model included male gender, IVIG resistance, NLR > 3.5, and CRP > $103 \mathrm{mg} / \mathrm{L}$. At the cut-off point of 2 points, the sensitivity was $60.8 \%$, and the specificity was $70.6 \%$, with an AUC of 0.696 . This scoring system can help clinicians with early recognition of high-risk patients and can lead to different treatment options.

\begin{abstract}
Abbreviations
ALT: Alanine aminotransferase; AST: Aspartate aminotransferase; AUC: Area under the curve of ROC; BCG: Bacille Calmette-Guerin; CAL: Coronary artery lesions; Cl: Confidence interval; CRP: C reactive protein; IVIG: Intravenous immunoglobulin; KD: Kawasaki disease; NLR: Neutrophil/lymphocyte ratio; NPV: Negative predictive value; PLR: Platelet/lymphocyte ratio; PPV: Positive predictive value; ROC: Receiver-operating-characteristics; WBC: White blood cells
\end{abstract}

\section{Acknowledgements}

We would like to thank Hsin-Yi Chien, Chih-Yun Lin, and Nien-Tzu Hsu, as well as the Biostatistics Center, Kaohsiung Chang Gung Memorial Hospital, for statistics work

\section{Authors' contributions}

LC and YL drafted the article, carried out conception, design, and initial analyses, and approved the final manuscript as submitted. JY, MG, and ML acquired, analyzed, interpreted data, reviewed the manuscript, and approved the final manuscript as submitted. HK carried out conception and design, acquired data, reviewed the manuscript, revised it for intellectual content, and approved the final manuscript as submitted. All authors have read and approved the manuscript.

\section{Funding}

This study was partially supported by grants from the Ministry of Science and Technology, Taiwan (MOST 108-2314-B-182 -037 -MY3) and Chang Gung Memorial Hospital (CMRPG8K0641, 8H1161; 8F1911, 1921, 1931, and 1941; 8E0212; and CORPG8F0012). Although these institutes provided financial support, they had no influence on the way in which we collected, analyzed, or interpreted the data or wrote this manuscript.

Ethics approval and consent to participate

Ethics committee approval was obtained from Kaohsiung Chang Gung Memorial Hospital's ethics committee (IRB 201601736A3C102) which allowed administrative permissions to access and use the medical records described 
in the study. There is no need for consent to participate to be obtained in this retrospective study.

\section{Consent for publication}

Not Applicable.

\section{Availability of data and materials}

The datasets used and/or analysed during the current study available from the corresponding author on reasonable request.

\section{Competing interests}

Professor Kuo as a member of the editorial board (Associate Editor) of this journal, the authors declare that they have no competing interests.

\section{Author details}

'Department of Pediatrics and Kawasaki Disease Center, Kaohsiung Chang Gung Memorial Hospital, Chang Gung University College of Medicine, \#123 Da-Pei Road, Niaosong District, 83301 Kaohsiung, Taiwan. ²Department of Pediatrics, Chiayi Chang Gung Memorial Hospital, Chiayi City, Taiwan.

Received: 14 April 2020 Accepted: 11 August 2020

Published online: 24 August 2020

\section{References}

1. Kawasaki T, Kosaki F, Okawa S, Shigematsu I, Yanagawa H. A new infantile acute febrile mucocutaneous lymph node syndrome (MLNS) prevailing in Japan. Pediatrics. 1974;54(3):271-6.

2. Makino N, Nakamura Y, Yashiro M, Ae R, Tsuboi S, Aoyama Y, Kojo T, Uehara $\mathrm{R}$, Kotani K, Yanagawa $\mathrm{H}$ : Descriptive epidemiology of Kawasaki disease in Japan, 2011-2012: from the results of the 22nd nationwide survey. J Epidemiol 2015, 25(3):239-245.

3. Newburger JW, Takahashi M, Gerber MA, Gewitz MH, Tani LY, Burns JC, Shulman ST, Bolger AF, Ferrieri P, Baltimore RS, et al. Diagnosis, treatment, and long-term management of Kawasaki disease: a statement for health professionals from the Committee on Rheumatic Fever, Endocarditis and Kawasaki Disease, Council on Cardiovascular Disease in the Young, American Heart Association. Circulation. 2004;110(17):2747-71.

4. Kuo HC. Preventing coronary artery lesions in Kawasaki disease. Biomed J. 2017:40(3):141-6.

5. Newburger JW, Takahashi M, Burns JC, Beiser AS, Chung KJ, Duffy CE, Glode MP, Mason WH, Reddy V, Sanders SP, et al. The treatment of Kawasaki syndrome with intravenous gamma globulin. N Engl J Med. 1986;315(6): 341-7.

6. Wu MH, Chen HC, Yeh SJ, Lin MT, Huang SC, Huang SK. Prevalence and the long-term coronary risks of patients with Kawasaki disease in a general population < 40 years: a national database study. Circ Cardiovasc Qual Outcomes. 2012;5(4):566-70.

7. de Ferranti SD, Gauvreau K, Friedman KG, Tang A, Baker AL, Fulton DR, Tremoulet AH, Burns JC, Newburger JW. Association of Initially Normal Coronary Arteries With Normal Findings on Follow-up Echocardiography in Patients With Kawasaki Disease. JAMA pediatrics. 2018;172(12):e183310.

8. Dominguez SR, Anderson MS, El-Adawy M, Glode MP. Preventing coronary artery abnormalities: a need for earlier diagnosis and treatment of Kawasaki disease. Pediatr Infect Dis J. 2012;31(12):1217-20.

9. Skochko SM, Jain S, Sun X, Sivilay N, Kanegaye JT, Pancheri J, Shimizu C, Sheets R, Tremoulet AH, Burns JC. Kawasaki Disease Outcomes and Response to Therapy in a Multiethnic Community: A 10-Year Experience. J Pediatr. 2018;203:408-15.e403.

10. Lech M, Guess J, Duffner J, Oyamada J, Shimizu C, Hoshino S, Farutin V, Bulik DA, Gutierrez B, Sarvaiya H, et al: Circulating Markers of Inflammation Persist in Children and Adults with Giant Aneurysms after Kawasaki Disease. Circulation Genomic and precision medicine 2019.

11. Hamada H, Suzuki H, Onouchi Y, Ebata R, Terai M, Fuse S, Okajima Y, Kurotobi S, Hirai K, Soga T, et al: Efficacy of primary treatment with immunoglobulin plus ciclosporin for prevention of coronary artery abnormalities in patients with Kawasaki disease predicted to be at increased risk of non-response to intravenous immunoglobulin (KAICA): a randomised controlled, open-label, blinded-endpoints, phase 3 trial. Lancet (London, England) 2019, 393(10176):1128-1137.
12. Portman MA, Dahdah NS, Slee A, Olson AK, Choueiter NF, Soriano BD, Buddhe S, Altman CA. Etanercept With IVlg for Acute Kawasaki Disease: A Randomized Controlled Trial. Pediatrics. 2019;2(10):2018-3675.

13. Newburger JW, Sleeper LA, McCrindle BW, Minich LL, Gersony W, Vetter VL, Atz AM, Li JS, Takahashi M, Baker AL, et al. Randomized trial of pulsed corticosteroid therapy for primary treatment of Kawasaki disease. N Engl J Med. 2007;356(7):663-75.

14. Yang TJ, Lin MT, Lu CY, Chen JM, Lee PI, Huang LM, Wu MH, Chang LY: The prevention of coronary arterial abnormalities in Kawasaki disease: A metaanalysis of the corticosteroid effectiveness. Journal of microbiology, immunology, and infection = Wei mian yu gan ran za zhi 2018, 51(3):321-331.

15. Chen S, Dong Y, Kiuchi MG, Wang J, Li R, Ling Z, Zhou T, Wang Z, Martinek $M$, Purerfellner $\mathrm{H}$, et al: Coronary Artery Complication in Kawasaki Disease and the Importance of Early Intervention: A Systematic Review and Metaanalysis. JAMA pediatrics 2016, 170(12):1156-1163.

16. Liu MY, Liu HM, Wu CH, Chang CH, Huang GJ, Chen CA, Chiu SN, Lu CW, Lin MT, Chang LY, et al. Risk factors and implications of progressive coronary dilatation in children with Kawasaki disease. BMC Pediatr. 2017; 17(1):139.

17. Hua W, Ma F, Wang Y, Fu S, Wang W, Xie C, Zhang Y, Gong F. A new scoring system to predict Kawasaki disease with coronary artery lesions. Clin Rheumatol 2018.

18. Deng YC, Wang X, Tang XC, Huang CZ, Yang J, Mo LY. [Risk factors for coronary artery lesions secondary to Kawasaki disease in children]. Zhongguo Dang Dai Er Ke Za Zhi. 2015;17(9):927-31.

19. Nakamura Y, Fujita Y, Nagai M, Yanagawa H, Imada Y, Okawa S, Kawasaki T, Kato H. Cardiac sequelae of Kawasaki disease in Japan: statistical analysis. Pediatrics. 1991;88(6):1144-7.

20. Zhang T, Yanagawa H, Oki I, Nakamura Y, Yashiro M, Ojima T, Tanihara S. Factors related to cardiac sequelae of Kawasaki disease. Eur J Pediatr. 1999; 158(9):694-7.

21. Belay ED, Maddox RA, Holman RC, Curns AT, Ballah K, Schonberger LB. Kawasaki syndrome and risk factors for coronary artery abnormalities: United States, 1994-2003. Pediatr Infect Dis J. 2006;25(3):245-9.

22. Rosenfeld EA, Corydon KE, Shulman ST. Kawasaki disease in infants less than one year of age. J Pediatr. 1995;126(4):524-9.

23. Muta H, Ishii M, Sakaue T, Egami K, Furui J, Sugahara Y, Akagi T, Nakamura Y, Yanagawa $\mathrm{H}$, Matsuishi T. Older age is a risk factor for the development of cardiovascular sequelae in Kawasaki disease. Pediatrics. 2004;114(3):751-4.

24. Son MBF, Gauvreau K, Tremoulet AH, Lo M, Baker AL, de Ferranti S, Dedeoglu F, Sundel RP, Friedman KG, Burns JC, et al. Risk Model Development and Validation for Prediction of Coronary Artery Aneurysms in Kawasaki Disease in a North American Population. Journal of the American Heart Association. 2019;8(11):e011319.

25. Dionne A, Burns JC, Dahdah N, Tremoulet AH, Gauvreau K, de Ferranti SD, Baker AL, Son MB, Gould P, Fournier A, et al: Treatment Intensification in Patients With Kawasaki Disease and Coronary Aneurysm at Diagnosis. Pediatrics 2019.

26. Tremoulet AH, Best BM, Song S, Wang S, Corinaldesi E, Eichenfield JR, Martin DD, Newburger JW, Burns JC. Resistance to intravenous immunoglobulin in children with Kawasaki disease. J Pediatr. 2008;153(1):117-21.

27. Ayusawa M, Sonobe T, Uemura S, Ogawa S, Nakamura Y, Kiyosawa N, Ishii M, Harada K, Kawasaki Disease Research C: Revision of diagnostic guidelines for Kawasaki disease (the 5th revised edition). Pediatr Int 2005, 47(2):232-234.

28. Chang LS, Ming-Huey Guo M, Lo MH, Kuo HC. Identification of increased expression of activating Fc receptors and novel findings regarding distinct IgE and IgM receptors in Kawasaki disease. Pediatr Res. 2019. https://doi.org/ 10.1038/s41390-019-0707-y.

29. Nanishi E, Nishio H, Takada H, Yamamura K, Fukazawa M, Furuno K, Mizuno Y, Saigo K, Kadoya R, Ohbuchi N, et al. Clarithromycin Plus Intravenous Immunoglobulin Therapy Can Reduce the Relapse Rate of Kawasaki Disease: A Phase 2, Open-Label, Randomized Control Study. Journal of the American Heart Association 2017, 6(7).

30. Chang LS, Guo MM, Yan JH, Huang YH, Lo MH, Kuo HC. Low FCMR mRNA expression in leukocytes of patients with Kawasaki disease six months after disease onset. Pediatric allergy and immunology: official publication of the European Society of Pediatric Allergy and Immunology. 2020;31:554-9.

31. Kobayashi T, Saji T, Otani T, Takeuchi K, Nakamura T, Arakawa H, Kato T, Hara T, Hamaoka K, Ogawa S, et al. Efficacy of immunoglobulin plus prednisolone for prevention of coronary artery abnormalities in severe Kawasaki disease 
(RAISE study): a randomised, open-label, blinded-endpoints trial. Lancet. 2012;379(9826):1613-20.

32. Chang LS, Kuo HC. The role of corticosteroids in the treatment of Kawasaki disease. Expert review of anti-infective therapy. 2020;18(2):155-64.

33. Egami K, Muta H, Ishii M, Suda K, Sugahara Y, lemura M, Matsuishi T. Prediction of resistance to intravenous immunoglobulin treatment in patients with Kawasaki disease. J Pediatr. 2006;149(2):237-40.

34. Kobayashi T, Inoue Y, Takeuchi K, Okada Y, Tamura K, Tomomasa T, Kobayashi T, Morikawa A. Prediction of intravenous immunoglobulin unresponsiveness in patients with Kawasaki disease. Circulation. 2006; 113(22):2606-12.

35. Sano T, Kurotobi S, Matsuzaki K, Yamamoto T, Maki I, Miki K, Kogaki S, Hara J. Prediction of non-responsiveness to standard high-dose gamma-globulin therapy in patients with acute Kawasaki disease before starting initial treatment. Eur J Pediatr. 2007;166(2):131-7.

36. Chen Y, Hua Y, Zhang C, Chen S, Zhang Q, Liao Y, Yan H, Wang Y, Liu P, Qi J, et al. Neutrophil-to-Lymphocyte Ratio Predicts Intravenous Immunoglobulin-Resistance in Infants Under 12-Months Old With Kawasaki Disease. Front Pead. 2019;7:81.

37. Nakano H, Ueda K, Saito A, Tsuchitani Y, Kawamori J, Miyake T, Yoshida T. Scoring method for identifying patients with Kawasaki disease at high risk of coronary artery aneurysms. Am J Cardiol. 1986;58(9):739-42.

38. Beiser AS, Takahashi M, Baker AL, Sundel RP, Newburger JW. A predictive instrument for coronary artery aneurysms in Kawasaki disease. US Multicenter Kawasaki Disease Study Group. Am J Cardiol. 1998;81(9):1116-20.

39. Kim JJ, Hong YM, Yun SW, Han MK, Lee KY, Song MS, Lee HD, Kim DS, Sohn $\mathrm{S}$, Ha KS, et al. Assessment of risk factors for Korean children with Kawasaki disease. Pediatr Cardiol. 2012;33(4):513-20.

40. Zahorec R. Ratio of neutrophil to lymphocyte counts-rapid and simple parameter of systemic inflammation and stress in critically ill. Bratisl Lek Listy. 2001;102(1):5-14.

41. Rigante D, Andreozzi L, Fastiggi M, Bracci B, Natale MF, Esposito S. Critical Overview of the Risk Scoring Systems to Predict Non-Responsiveness to Intravenous Immunoglobulin in Kawasaki Syndrome. Int J Mol Sci. 2016; 17(3):278

42. Amano S, Hazama F, Kubagawa H, Tasaka K, Haebara H, Hamashima Y. General pathology of Kawasaki disease. On the morphological alterations corresponding to the clinical manifestations. Acta Pathol Jpn. 1980;30(5):681-94.

43. Ha KS, Lee J, Jang GY, Lee J, Lee KC, Son CS, Lee JW. Value of neutrophillymphocyte ratio in predicting outcomes in Kawasaki disease. Am J Cardiol. 2015;116(2):301-6.

44. Takeshita S, Kanai T, Kawamura Y, Yoshida Y, Nonoyama S. A comparison of the predictive validity of the combination of the neutrophil-to-lymphocyte ratio and platelet-to-lymphocyte ratio and other risk scoring systems for intravenous immunoglobulin (ivig)-resistance in Kawasaki disease. PLoS One. 2017;12(5):e0176957.

\section{Publisher's Note}

Springer Nature remains neutral with regard to jurisdictional claims in published maps and institutional affiliations.

Ready to submit your research? Choose BMC and benefit from:

- fast, convenient online submission

- thorough peer review by experienced researchers in your field

- rapid publication on acceptance

- support for research data, including large and complex data types

- gold Open Access which fosters wider collaboration and increased citations

- maximum visibility for your research: over $100 \mathrm{M}$ website views per year

At BMC, research is always in progress.

Learn more biomedcentral.com/submissions 